\title{
Implications of cleaved caspase 3 and AIF expression in colorectal cancer based on patient age
}

\author{
AURÉLIE PERRAUD ${ }^{1,2,4}$, HUSSEIN AKIL ${ }^{1,2}$, MICHELLE NOUAILLE ${ }^{4}$, DANIEL PETIT ${ }^{3}$, \\ FRANÇOIS LABROUSSE ${ }^{5}$, MARIE-ODILE JAUBERTEAU ${ }^{1,2}$ and MURIEL MATHONNET ${ }^{1,2,4}$
}

\author{
${ }^{1}$ Limoges University, EA 3842 Laboratory, Homéostasie Cellulaire et Pathologies, Medicine and Pharmacy Faculties, \\ 87025 Limoges Cedex, ${ }^{2}$ Limoges University, Institut Fédératif de Recherche 145 GEIST ‘Génomique, \\ Environnement, Immunité, Santé et Thérapeutiques' ${ }^{3}$ Limoges Teaching Hospital, Digestive \\ General and Endocrine Surgery Department, ${ }^{4}$ UMR 1061 INRA, Limoges University, 87060 \\ Limoges Cedex, ${ }^{5}$ Limoges Teaching Hospital, Anatomopathology Department, France
}

Received November 17, 2011; Accepted December 9, 2011

DOI: $10.3892 /$ or.2012.1737

\begin{abstract}
A high incidence of colorectal cancer (CRC) has been established in the elderly population. Apoptosis is a key event in maintaining colon homeostasis, both in aging as well as in cancer prevention. Here, we report that colon morphology is affected during the aging process: crypt loss $(\mathrm{P}=0.045)$ and increasing distances between crypts $(\mathrm{P}=0.0001678)$ were observed, associated with a tendency for mucosa reduction $(\mathrm{P}=0.083)$. In addition, our results show that apoptosis plays a determining role on the effect of aging during CRC. Increased expression of cleaved caspase 3 (the key factor implicated in the caspase-dependent pathway; $\mathrm{P}=0.026$ for non-tumor tissues, $\mathrm{P}=0.0013$ for tumor tissues) and AIF (implicated in the caspase-independent pathway; $\mathrm{P}=0.037$ ) in tissue from elderly patients has been observed. Furthermore, elderly patients respond better to chemotherapy than younger ones $\left(\mathrm{P}=9.27 \times 10^{-5}\right)$. These results suggest that patient age should be taken into account to adapt treatment of CRC.
\end{abstract}

\section{Introduction}

Defined by the international pathology tumor node metastasis (pTNM) classification system (1), colorectal cancer (CRC) is characterized by four distinct tumor stages of development. Because this disease represents the second most common cancer among men and the third among women (2), intensive research is underway to improve CRC patient quality of life. In fact, in spite of available therapies, the survival rate remains very low (National Cancer Institute data).

Correspondence to: Dr Aurélie Perraud, Limoges University, EA 3842 Laboratory, Homéostasie Cellulaire et Pathologies, Medicine and Pharmacy Faculties, 2 rue du Dr Marcland, 87025 Limoges Cedex, France

E-mail: aurelie.perraud@unilim.fr

Key words: colorectal cancer, apoptosis, age, treatment
Aging is accompanied by molecular and functional changes which can contribute to high incidences of cancer. Cancer is rare before the age of 40 but this rate increases from age 40 to 75 , making cancer a very common occurrence in the elderly (3). There is a high incidence of CRC in the elderly population; indeed, the average age at the time of diagnosis is 70 years old.

A strict control of apoptosis is especially important to maintain homeostasis for mitotic tissue such as colon in which cells continuously proliferate and have a short life cycle. A balance is maintained in the epithelial cell compartment between proliferation at the base of the crypt and apoptosis (associated with other cell loss) largely at the luminal surface of the colonic crypt. Increasing apoptosis without enhancing cell differentiation is not desirable as it causes loss of tissue structure and function, further contributing to aging. However, over-activation of apoptosis which occurs with aging accompanies tissue dysfunction and altered tissue architecture (4), making regulation of apoptosis pathways a significant event in aging.

In the case of CRC, a particularly common disease in elderly people, chemotherapy is not recommended for patients $>80$ years old. Adapting treatment based on patient age and co-morbidity is already performed and needs to be extended, especially with the growing importance of individualized therapy. Moreover, studying age-related differences in apoptosis may improve CRC understanding.

Apoptosis is a programmed cell death activated by two major pathways: the extrinsic or death receptor pathway and the intrinsic or mitochondrial pathway which are linked by activation of caspase 3 (reviewed in ref. 5). To obtain an overview of this process, we chose to examine the expression of cleaved caspase 3 , the pivotal factor implicated in the execution of celldeath-dependent caspase activation (6). We also assessed AIF (apoptosis inducing factor) expression because of its essential role in caspase-independent apoptosis $(7,8)$. We believe that a more effective treatment against cancer will be achieved using drugs that induce programmed cell death by both dependent and independent pathways of caspase activation. Studying proteins implicated in these two distinct pathways will provide important information. 
To our knowledge, there are no reports on the influence of aging on the expression of factors that regulate colonic epithelial proliferation and apoptosis both in non-tumor (NT) and tumor $(\mathrm{T})$ areas of patients with different CRC stages. Thus, the aim of our study was to identify a link between age and essential pro-apoptotic protein expression, cleaved caspase 3 and AIF, during the development of CRC.

\section{Materials and methods}

Patient characteristics. Our study group of 82 patients with histologically proven CRC admitted to the Limoges University Hospital, and treated for CRC between January 2006 and February 2007, were examined with a median follow up of 33 months (range, $0-45$ months). The exclusion criteria as described by the Helsinki protocol were: juvenile patients, pregnant or breast-feeding women, rectal or colonic lesions that were not histologically proven, patients with impossible follow-up, and insufficient or unexploitable tissue because of inadequate preservation.

Eighty-two patients (38 women and 44 men), with a mean age of 71 years (range, 41-93 years), were included prospectively. Tumors were graded according to the pTNM international classification (1). Forty patients had local disease (stage I, T1/2-N0, n=6; stage II, T3/4-N0, n=35), 27 had regional lymph-node involvement (stage III, any T-N1/2), and 14 had advanced disease (stage IV, any T, any N, presence of metastasis). Patient characteristics are summarized in Table I. Patients were followed-up as recommended (9). The last follow-up evaluation was performed on September 1, 2009. FOLFOX4 was the standard treatment administered.

The control group, with a medium age of 66 years, was formed by histologically normal colons from 16 patients, treated for benign pathologies such as intestinal ischemia $(n=1)$, polyps $(n=2)$, appendicitis $(n=2)$, dolichomegacolon $(\mathrm{n}=3)$ or diverticulosis $(\mathrm{n}=8)$.

Patient follow-up and clinical pathology. Clinical, paraclinical (biology and imagery) and histological parameters were collected by Michelle Nouaille and Pathology Department technicians. The recommended post-operative follow-up (9) was performed as previously described (10). Recurrence-free and disease-specific survivals were analyzed and are presented in Table II.

Tissue samples. Archived, formalin-fixed and paraffinembedded blocks of tissues were obtained from the Pathology Department of the Limoges Teaching Hospital. Tissues were sectioned $(4 \mu \mathrm{m})$ and stained with HES for pathological diagnosis and TNM grading with the pTNM system (1) as well for studying the morphology and for immunostaining. Histological slides were reviewed to identify normal-appearing areas and also tumor areas, excluding the necrotic central tumor zone.

Immunohistochemistry. Antibodies used were previously assessed by western blot analysis for AIF [Santa Cruz Biotechnology, sc-9416 (D-20)] (11) and for immunohistochemistry for cleaved caspase 3 (Cell Signaling, no. 9661) (12).

Paraffin sections were deparaffinized in toluene, alcohol and rehydrated with phosphate-buffered saline (PBS). Before
Table I. Global patient characteristics.

\begin{tabular}{|c|c|c|c|c|c|c|}
\hline \multirow[b]{2}{*}{ Characteristics } & \multicolumn{2}{|c|}{$\begin{array}{l}\text { Patients } \\
<70 \text { years }\end{array}$} & \multicolumn{2}{|c|}{$\begin{array}{l}\text { Patients } \\
>70 \text { years }\end{array}$} & \multicolumn{2}{|c|}{ Total } \\
\hline & $\mathrm{N}$ & $\%$ & $\mathrm{~N}$ & $\%$ & $\mathrm{~N}$ & $\%$ \\
\hline Gender & & & & & 82 & 100.0 \\
\hline Male & 13 & 15.8 & 31 & 37.8 & 44 & 53.6 \\
\hline Female & 11 & 13.4 & 27 & 32.9 & 38 & 46.3 \\
\hline \multicolumn{7}{|l|}{ pTNM stage } \\
\hline I & 2 & 8.3 & 4 & 6.9 & 6 & 7.3 \\
\hline II & 6 & 25.0 & 29 & 50.0 & 35 & 42.7 \\
\hline III & 7 & 29.2 & 20 & 34.5 & 27 & 32.9 \\
\hline IV & 9 & 37.5 & 5 & 8.6 & 14 & 17.1 \\
\hline \multicolumn{7}{|l|}{ ASA scores } \\
\hline $1-2$ & 23 & 28.0 & 32 & 39.0 & 55 & 67.1 \\
\hline $3-4$ & 1 & 1.2 & 26 & 31.7 & 27 & 32.9 \\
\hline
\end{tabular}

Table II. Patient outcome.

\begin{tabular}{|c|c|c|c|c|c|c|}
\hline & \multicolumn{2}{|c|}{$\begin{array}{l}\text { Patients } \\
<70 \text { years }\end{array}$} & \multicolumn{2}{|c|}{$\begin{array}{l}\text { Patients } \\
>70 \text { years }\end{array}$} & \multicolumn{2}{|c|}{ Total } \\
\hline & $\mathrm{N}$ & $\%$ & $\mathrm{~N}$ & $\%$ & $\mathrm{~N}$ & $\%$ \\
\hline Total survival & 18 & 75.0 & 31 & 53.4 & 49 & 59.7 \\
\hline \multicolumn{7}{|c|}{ Recurrence-free survival } \\
\hline Total & 15 & 62.5 & 28 & 48.3 & 43 & 52.4 \\
\hline Stage I & 2 & & 4 & & & \\
\hline Stage II & 6 & & 14 & & & \\
\hline Stage III & 4 & & 9 & & & \\
\hline Stage IV & 3 & & 1 & & & \\
\hline \multicolumn{7}{|c|}{ Disease-specific survival } \\
\hline Total & 3 & 12.5 & 3 & 5.2 & 6 & 7.3 \\
\hline Stage II & 0 & & 2 & & & \\
\hline Stage III & 2 & & 0 & & & \\
\hline Stage IV & 1 & & 1 & & & \\
\hline Total death & 6 & 25.0 & 27 & 46.5 & 33 & 40.2 \\
\hline \multicolumn{7}{|c|}{ Death due to CRC } \\
\hline Total & 5 & 20.8 & 15 & 25.9 & 20 & 24.4 \\
\hline Stage II & 0 & & 3 & & & \\
\hline Stage III & 0 & & 9 & & & \\
\hline Stage IV & 5 & & 3 & & & \\
\hline \multicolumn{7}{|c|}{ Due to other causes } \\
\hline Total & 1 & 4.2 & 12 & 20.7 & 13 & 15.8 \\
\hline Stage II & 0 & & 10 & & & \\
\hline Stage III & 1 & & 2 & & & \\
\hline
\end{tabular}

staining, sections were subjected to steam heat antigen retrieval in citrate buffer $(200 \mu \mathrm{M}$ citric acid, $9.8 \mathrm{mM}$ sodium citrate, $\mathrm{pH}$ 7.0) for $5 \mathrm{~min}$. This step was repeated four times in a microwave oven $(750 \mathrm{~W})$. After washing in PBS, slides 
were incubated for 10 min with $5 \% \mathrm{H}_{2} \mathrm{O}_{2}$ in methanol to inhibit endogenous peroxidases. Non-specific sites were blocked with PBS-3\% bovine serum albumin (BSA) for $30 \mathrm{~min}$. Samples were incubated for $1 \mathrm{~h}$ at $37^{\circ} \mathrm{C}$ with primary antibodies diluted in PBS-3\% BSA at 1:1000 for anti-AIF and 1:50 for cleaved caspase 3 . Because the antibody used against AIF is a horseradish peroxidase-coupled antibody, no secondary antibody was needed. For the detection of cleaved caspase 3, an anti-rabbit-HRP was added (30 min). Finally, proteins were detected using the chromogenic substrate DAB (5 min). Tissue sections were then counterstained with hematoxylin $(10 \mathrm{sec})$ and a bluing reagent $(10 \mathrm{sec})$ to increase contrast. Slides were conserved with non-aqueous mounting medium. The sections were examined and images were acquired with a Leica camera.

To test signal specificity, negative control experiments were performed either by omitting the primary antibody or by omitting both the primary and secondary antibodies. No staining was observed (data not shown).

Scoring method. The most homogeneous non-tumor and tumor-stained areas of each slide were selected for quantification. AIF immunoreactivity was scored as $0,25,50$ and $75 \%$ of stained cells. Cleaved caspase 3 was quantified as 0,10 , 25 and $50 \%$ of stained cells. Three independent examinations were performed on each slide by two individuals.

Statistics. Correlations between parameters were assessed as previously described (10). Kruskal-Wallis tests were conducted with PAST 2.03 (13) due to the unequal distribution between the parameters examined (number of crypts, thickness of mucosa and distance between crypts). P-values $<0.05$ were considered to denote significant differences.

\section{Results}

Patient characteristics and outcome. For the analysis, patients were divided in two distinct groups based on age with 70 years as the cut-off (Fig. 1). As shown in Table I, although the total number of patients in each group was quite different (24 vs. 58), both groups were homogeneous in terms of gender $(\mathrm{P}>0.5)$, with an $\sim 1$ :1 ratio. On the other hand, CRC stage distribution was clearly different between the two groups (Fig. 1, P=0.013). This result is certainly due to the higher number of stage II and III CRC specimens (the most common forms of CRC) observed in the patients $>70$ years group. Moreover, this large difference is linked to the number of patients with a CRC stage IV: 5 patients in the patients $>70$ years group which represent $6.1 \%$ of the total of analyzed patients; while they were 9 patients in the patients $<70$ years group which represent $11 \%$ of the total analyzed patients. This result is in agreement with previous reports which have shown that young people are more likely to have advanced and aggressive CRC than older individuals (14). As expected, these two groups are largely different in terms of their ASA score (American Society of Anesthesiologists; $\mathrm{P}=0.00021)$ : a high proportion $(31.7 \%)$ of patients in the patients $>70$ years group had ASA scores of 3-4, certainly due to their advanced age which is largely and commonly linked to development of various disorders (Table I). In terms of total survival, both groups were comparable with a higher proportion of patients having recurrence-free survival (62.5 and

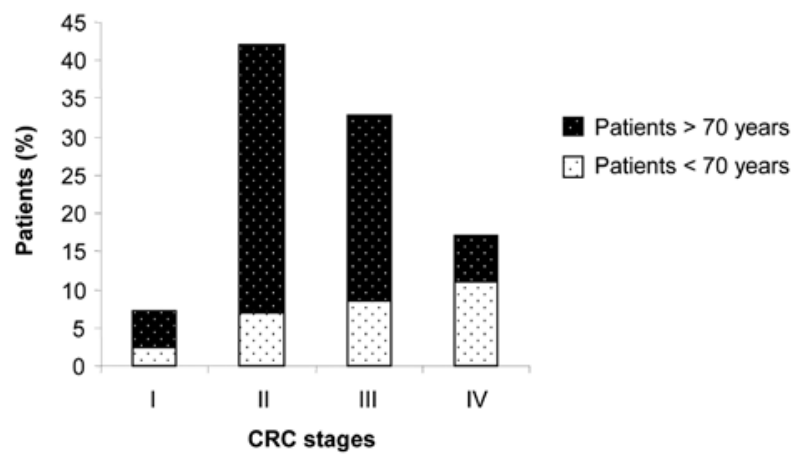

Figure 1. Percentage of patients in each CRC stage.

$48.3 \%$, respectively) than patients having a disease-specific survival (12.5 and 5.2\% for each group, respectively; Table II). The survival of patients in early or advanced stages did not show a significant difference between the groups but demonstrated that the younger the patient, the better the survival, regardless of pTNM stage (data not shown). Similarly, the two groups were comparable in terms of death due to CRC (20.8 vs. $25.9 \%$ ). In contrast, the death due to other causes was different: for the patients $<70$ years group, only 1 patient died vs. 12 in the patients $>70$ years group ( 4.2 vs. $20.7 \%$ ). This last result can be explained by the fact that elderly people have more medical problems, while young ones have a greater life expectancy. Samples of CRC and neighboring non-tumor mucosa were obtained at the time of resection following diagnosis.

Morphology of the colon mucosa differs with aging. Kwon and Magnuson have shown that young rats have densely populated crypts; middle-aged and old rats have fewer crypts per area, more damaged crypts (loss of bottom third or two-thirds) and evidence of crypt loss (15). To test if this result was transposable to humans, morphology of the colon mucosa from the control group was studied closely, without taking into consideration patient age at the time of analysis. Based on the observation of different HES slides for each patient, a descriptive study was performed by examining the thickness of the mucosa, the number of crypts and the relative distance between the crypts (see Materials and methods and the legend of Fig. 2 for details on the description of histology measurements). Although we assumed that it was impossible that all sections had exactly the same orientation, three major morphological differences were found (Fig. 2) and the significance of the analyzed parameters between both groups was assessed by Kruskal-Wallis tests. The number of crypts was diminished (a medium of 15.5 crypts/ area in young patients vs. 11 in elderly patients, $\mathrm{P}=0.045$ ), the thickness of the mucosa tended to be reduced in elderly patients (a medium of $1.8 \mathrm{~cm}$ in young patients vs. $2.3 \mathrm{~cm}$ in elderly patients, the Kruskal-Wallis test shows only a tendency with $\mathrm{P}=0.083$ ) and the distance between crypts is greater in elderly patients, in particular, as observed for patients $\mathrm{K}, \mathrm{M}$ and P (Fig. 2; a medium of $0.91 \mathrm{~mm}$ between crypts in young patients vs. $1.67 \mathrm{~mm}$ in elderly patients, with $\mathrm{P}=0.0001678$ ). In spite of the fact that these results are descriptive and only based on personal observations, they were significant and confirmed that aging is accompanied by morphological changes in the human colon mucosa. 

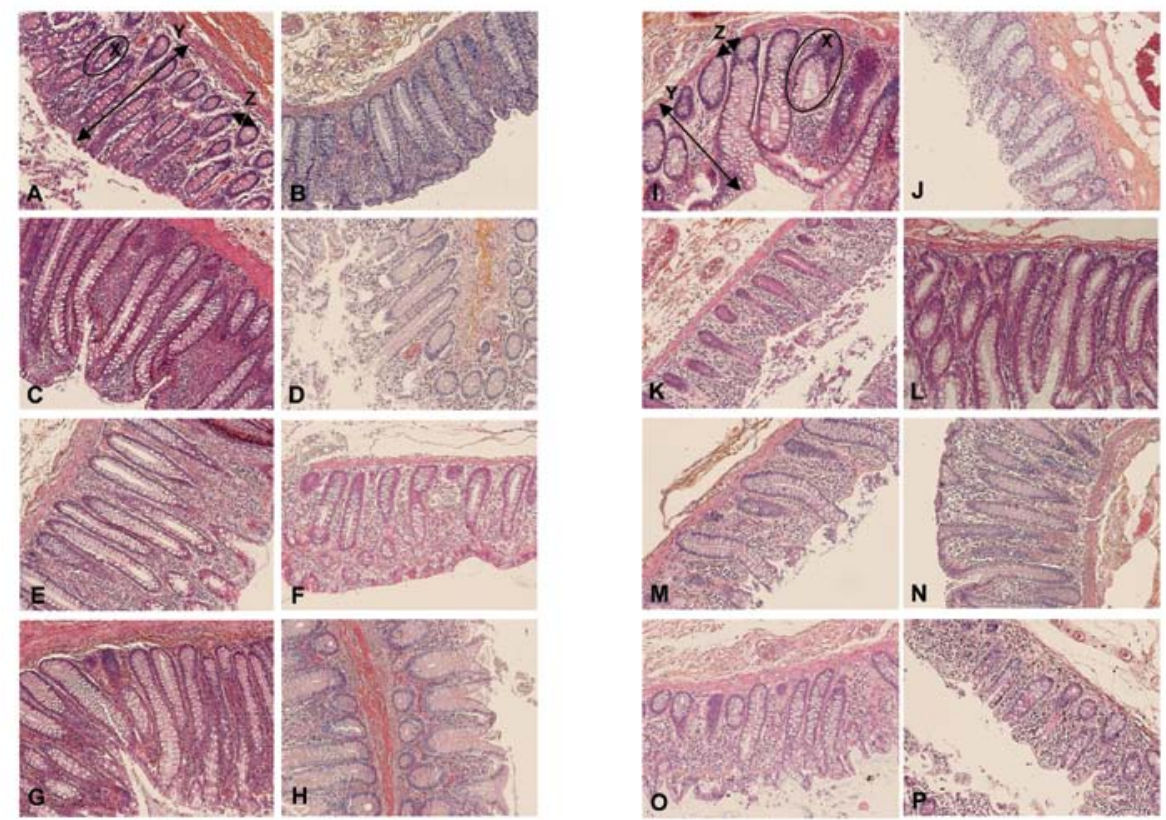

Figure 2. Morphology of normal colon mucosa from patients with different ages. Patients in the control group were chosen to evaluate three parameters in their normal mucosa stained by HES. The number of crypts/field was determined by counting all crypts in the field for each patient ( $15.5 \mathrm{crypts} /$ field in young patients vs. 11 in old patients, confirmed by the Kruskal-Wallis test, $\mathrm{P}=0.045)$. Mucosal thickness was determined by measuring the distance between the crypt apex and the muscular mucosa. Three measurements were made on the same field to obtain an average for each patient $(1.8 \mathrm{~cm}$ in young patients vs. $2.3 \mathrm{~cm}$ in old patients, Kruskal-Wallis test shows only a tendency with $\mathrm{P}=0.083$ ). The distance between crypts was measured in three distinct areas to obtain an average for each patient $(0.91 \mathrm{~mm}$ between crypts in young patients vs. $1.67 \mathrm{~mm}$ in old patients, with $\mathrm{P}=0.0001678$ by the Kruskal-Wallis test). Original magnification, x100. (A-H) Patients $<70$ years. (I-P) Patients $>70$ years.
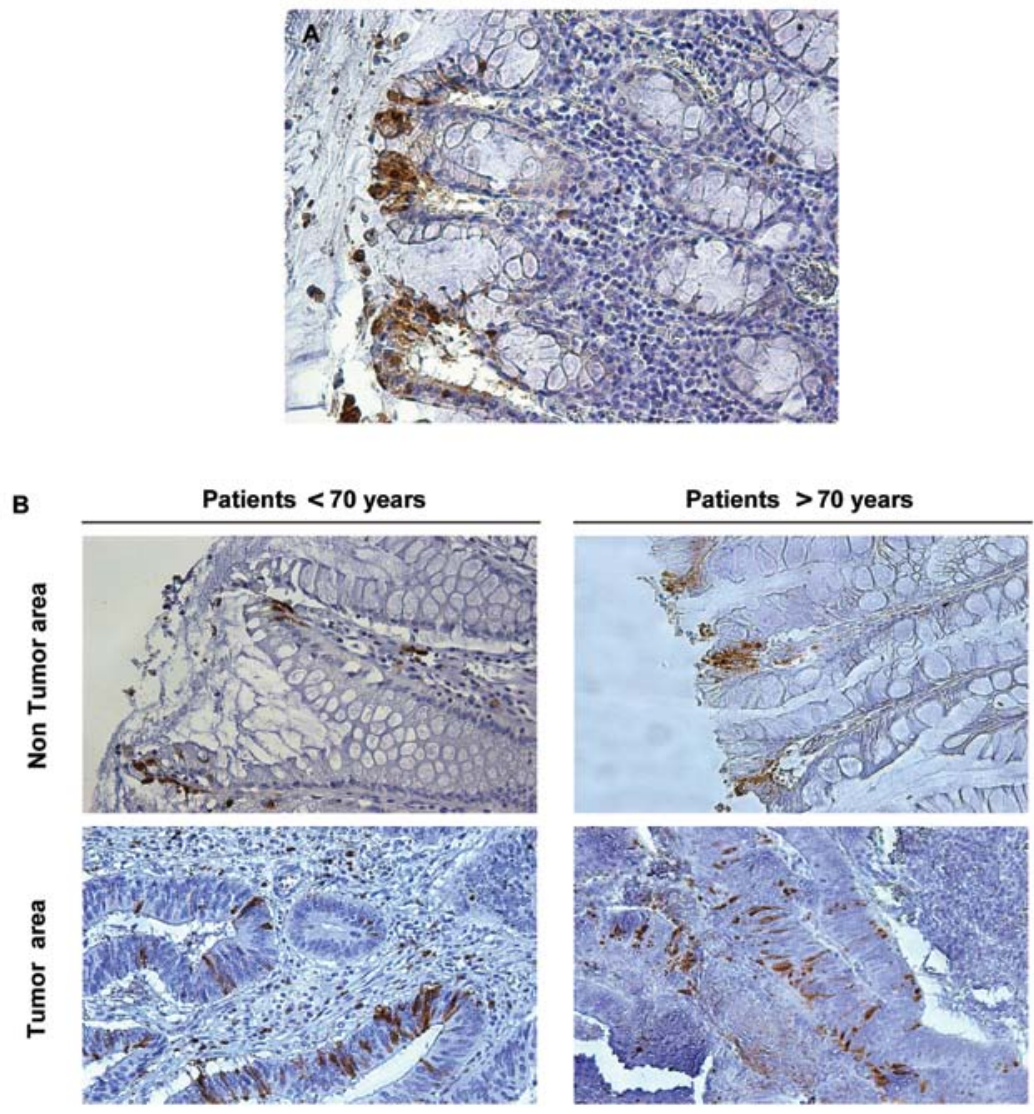

Figure 3. Cleaved caspase 3 expression in non-tumor and tumor tissues from CRC patients at different ages. Immunohistochemical staining was performed on paraffin-embedded sections $(4 \mu \mathrm{m})$, using anti-cleaved caspase 3 antibody. Original magnification, $\mathrm{x} 200$. Immunoreactivity was scored as percentages of stained cells $(0,25$ and $50 \%)$. Three independent examinations were performed for each slide by two individuals. Semi-quantitative analysis revealed a significant difference between the two analyzed groups: non-tumor tissue ( $\mathrm{P}=0.026)$ and tumor tissue $(\mathrm{P}=0.0013)$. (A) Control patients. (B) CRC patients. 


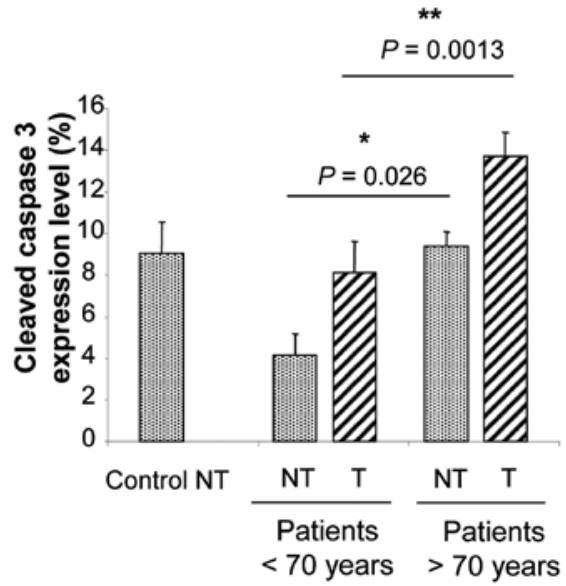

Figure 4. Influence of age on cleaved caspase 3 expression in tissue from CRC patients. NT, non-tumor areas. T, tumor areas. ${ }^{*} \mathrm{P}<0.05 ;{ }^{* *} \mathrm{P}<0.01$.

Increased expression of cleaved caspase 3 with aging. Cleaved caspase 3 (cysteinyl aspartate specific proteases) is a key effector of apoptosis. Caspase 3 is present in healthy cells as a $32-\mathrm{kDa}$ proenzyme that is cleaved to form the active heterodimer $(17 / 12 \mathrm{kDa})$ prior to the onset of apoptosis. Once cleaved through the activation of the apoptotic cascade, the peptide end of this active caspase represents a novel epitope not present in normal cells, which is a unique and sensitive indicator of apoptosis (6).

As expected, cleaved caspase 3 staining was restricted to epithelial cells, at the border of the crypts (Fig. 3) and $10 \%$ of the cells were undergoing apoptosis in non-cancerous mucosa (control NT) as previously demonstrated (16). A significant correlation between patient age and cleaved caspase 3 expression was observed in our study. A distinct increase in cleaved caspase 3 expression was found for patients $>70$ years group (Figs. 3 and 4) in NT as well as in $\mathrm{T}$ areas $[\mathrm{P}=0.026$ and 0.0013, respectively; (Fig. 4)]. This finding was specific to CRC patients as it was not found in the control group divided with the same criteria (data not shown). These results suggest the implication of a caspase-dependent pathway of apoptosis in CRC development as shown by a stronger activation of this protein in elderly CRC patients.

Increased expression of AIF in NT tissue with aging. Usually, after apoptotic stimuli, AIF is released into the cytosol from the mitochondrial intermembrane where it interacts with cyclophilin A to become a DNase. Subsequently, when AIF is translocated to the nucleus, this may contribute to DNA fragmentation leading to cell death (17).
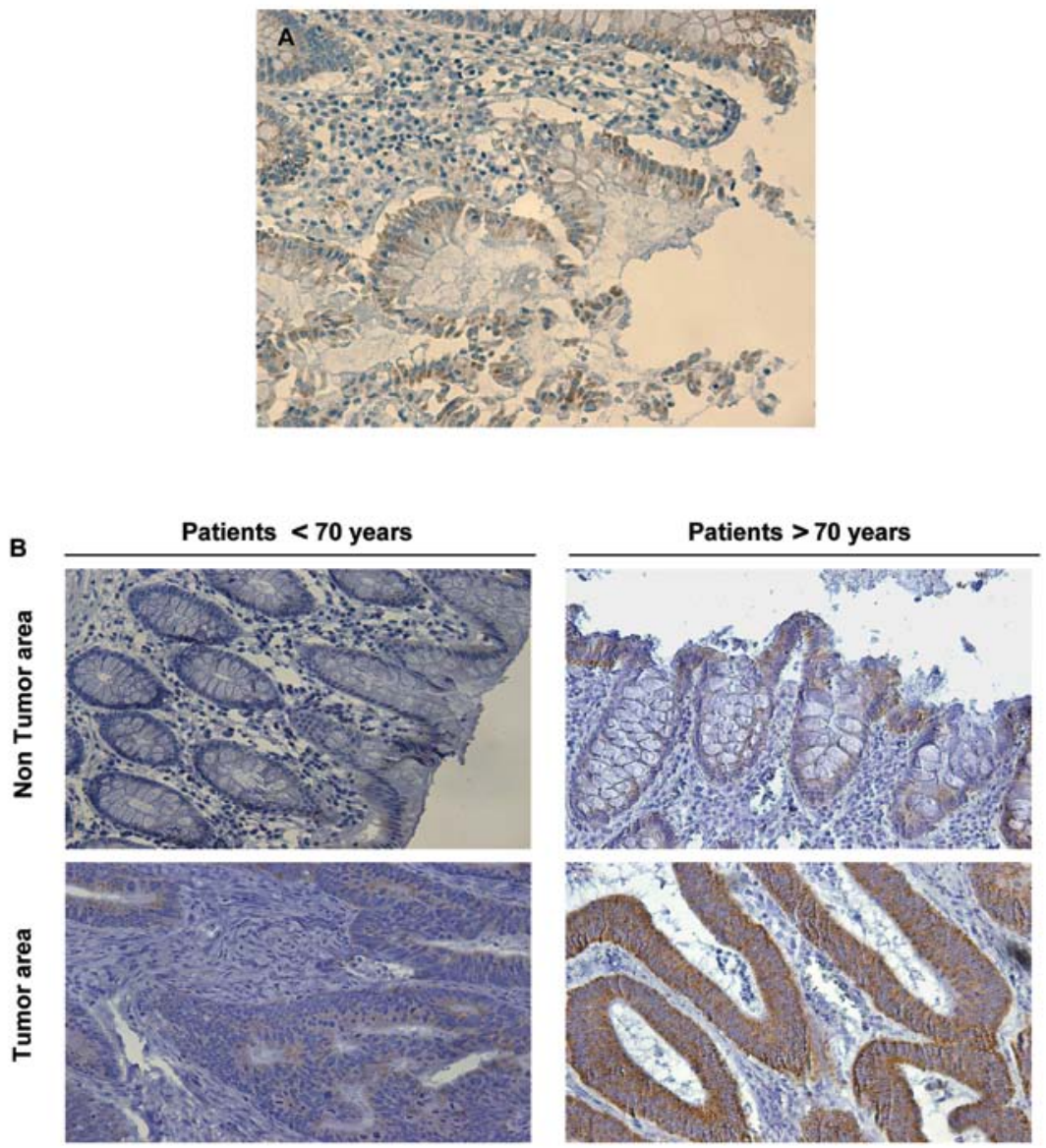

Figure 5. AIF expression in non-tumor and tumor tissues of CRC patients at different ages. Immunohistochemical staining was performed on paraffinembedded sections $(4 \mu \mathrm{m})$, using an anti-AIF antibody. Original magnification, $\mathrm{x} 200$. AIF immunoreactivity was scored as percentages of stained cells $(0$, 25,50 and $75 \%$ ). Three independent examinations were performed for each slide by two individuals. The difference was only significant for non-tumor tissue $(\mathrm{P}=0.037)$. (A) Control patients. (B) CRC patients. 


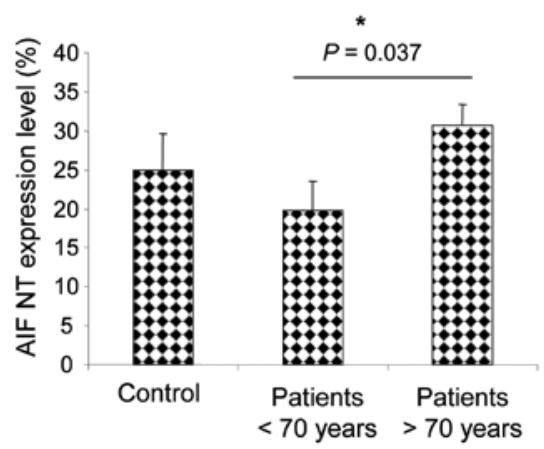

Figure 6. Influence of age on AIF expression in non-tumor areas of CRC patients. ${ }^{\mathrm{P}}<0.05$.

Table III. Clinical outcome of patients receiving chemotherapy.

\begin{tabular}{|c|c|c|c|c|}
\hline \multirow[b]{2}{*}{ Characteristics } & \multicolumn{2}{|c|}{$\begin{array}{l}\text { Patients } \\
<70 \text { years }\end{array}$} & \multicolumn{2}{|c|}{$\begin{array}{l}\text { Patients } \\
>70 \text { years }\end{array}$} \\
\hline & $\mathrm{N}$ & $\%$ & $\mathrm{~N}$ & $\%$ \\
\hline Survival & 11 & 68.75 & 5 & 71.4 \\
\hline Death & 5 & 31.25 & 2 & 28.6 \\
\hline Total & 16 & & 7 & \\
\hline
\end{tabular}

A relatively high level of AIF ( $>20 \%)$ was found for the control group (Fig. 6). This result was probably due to the damaged cells during surgery, the rapid deterioration of non-cancerous tissues (highly subject to ischemia) and the time required for the surgical pieces to be transported to the Pathology Department. Furthermore, the number of patients included in the control group was lower than the total number of analyzed patients, which could explain the difference obtained between the control group and the NT tissues from each patient group. As for cleaved caspase 3, AIF expression in NT tissues was higher in elderly compared to young patients ( $\mathrm{P}=0.037$; Figs. 5 and 6). This data was not transposable to the control group but was specific of CRC patients. Therefore, in the NT area, which represents the tumor environment, deregulations have already occurred, especially in elderly patients. These results suggest the involvement of the caspaseindependent pathway of apoptosis in events occurring in areas next to the cancerous tissue and also its role in aging.

Increased sensitivity to chemotherapy in elderly people. Interestingly, we found that the age at the time of surgical intervention (or at diagnosis) and chemoresistance were negatively correlated $\left(\mathrm{P}=9.27 \times 10^{-5}\right)$. Results from the entire study group showed that elderly patients were more chemosensitive than younger ones. Within the patients $>70$ years group, only 7 were treated by chemotherapy (which represents $12.1 \%$ of elderly patients or $8.5 \%$ of the total analyzed patients) and 49 did not receive treatment because of personal refusal, co-morbidity, being $>80$ years, or general damaged condition. Among the 7 patients who were treated by chemotherapy, 5 had survived (which represents $71.4 \%$ of elderly patients) and 2 had died at the time of analysis (representing 28.6\% of elderly patients). In contrast, within the patients $<70$ years group, only 16 were treated by chemotherapy (which represents $66.7 \%$ of young patients or $19.5 \%$ of the total analyzed patients). Among them, 11 had survived (68.75\%) and 5 had died $(31.25 \%)$ at the time the data were analyzed (Tables I-III). This data reinforces the fact that elderly patients treated by chemotherapy have a better clinical outcome than young ones. In conclusion, these results strongly suggest that age has to be taken in close consideration for treatment selection, especially in elderly patients.

\section{Discussion}

CRC is a cancer particularly affecting elderly people. However, studies rarely consider the aging effects on disease development and differences in carcinogenesis may contribute to the differential response to treatment. Data on the status of apoptotic protein expression in CRC are numerous and often controversial. To our knowledge, the relationship between apoptosis and age at CRC diagnosis has not been described.

Apoptosis increases dramatically with age upon exposure to genotoxic and cytotoxic carcinogens in the colon, giving rise to altered and defective colon architecture (15). Life time exposure to genotoxic substances and the high incidence of apoptosis that occurs during aging could cause changes in tissue morphology, leading to fewer crypts per area in the colon of older rats compared to younger ones (15). As found in animals, altered morphology of the colon mucosa was observed in our study (Fig. 2). These results reinforce the idea that the aging process affects the morphology of organs and, as a consequence, probably their functions. In fact, due to telomere shortening, aging is accompanied, on one hand, by apoptosis in normal physiological conditions and, on the other hand, is linked to tumorigenesis in pathological conditions, such as cancer (18).

For this purpose, expression of cleaved caspase 3 and AIF in tissues of patients having CRC at different tumor stages and correlation with patient age was studied. The marked increase in cleaved caspase 3 (reflecting the caspase-dependent pathway; Figs. 3 and 4) and AIF (representing the caspaseindependent pathway; Figs. 5 and 6) in CRC may reflect an increase in the proportion of cells that should have undergone spontaneous apoptosis (19). These results are in agreement with results obtained by $\mathrm{Li}$ and co-workers who have shown that aging is in part due to an increase in apoptosis (20). Cell loss during aging is related to increased sensitivity to apoptosis. Moreover, the biological behavior of cancer is known to be less aggressive in elderly people. An increased frequency of apoptosis in CRC tissues, especially in the earlier stages, may possibly explain the slower growth of CRC in the elderly (14). Due to telomere shortening, a programmed mechanism that triggers apoptosis becomes activated with age in post-mitotic tissues, such as the colon $(18,21)$. Aging is characterized by chronic production of radical intermediates in all tissues, which may promote apoptosis induction with time. Apoptosis may serve to eliminate non-functional, harmful, abnormal or misplaced cells especially in advanced age (21). In fact, ageenhanced apoptosis may be a protective mechanism to fight age-associated tumorigenesis $(18,21)$. 
In the present study, the data on the chemotherapy response of elderly patients demonstrate that elderly patients are more able to respond to standard treatment than younger ones $\left(\mathrm{P}=9.27 \times 10^{-5}\right)$. These findings provide important information related to the high incidence of CRC in the aged population and suggest that treatment needs to be adapted especially for elderly patients as recently described (22).

In conclusion cancer in the elderly and young people is variable and should be treated differently. As suggested by Colonna and co-workers, better diagnosis and an adapted treatment for the elderly, with further development of oncogeriatrics, is urgently needed (23). In agreement with this finding, specific treatment needs to be developed by combining the expertise of oncologists and geriatric physicians to better codify and adapt treatments based on patient age.

\section{Acknowledgements}

Part of this study was supported by the University of Limoges, La Ligue contre le Cancer and the Région Limousin (A.P.). H.A. is the recipient of a grant from the Conseil Régional du Limousin. We express our gratitude to Professor Descottes recently deceased, Professor Valleix and Professor Gainant (head of Surgery Department), to the Pathology Department technical experts of Limoges Teaching Hospital for their helpful advice on immunohistochemistry and to 'La tumorothèque du Limousin' for providing samples. We thank Dr Cook-Moreau for her editorial assistance.

\section{References}

1. Greene FL, Page DL, Fleming I, et al: AJCC (American Joint Committee on Cancer) Cancer Staging Manual. 6th edition. Springer-Verlag, New York, p113, 2002.

2. Bossard N, Velten M, Remontet L, et al: Survival of cancer patients in France: a population-based study from The Association of the French Cancer Registries (FRANCIM). Eur J Cancer 43: 149-160, 2007.

3. Benson D, Mitchell N and Dix D: On the role of aging in carcinogenesis. Mutat Res 356: 209-216, 1996.

4. Campisi J and Yaswen P: Aging and cancer cell biology, 2009. Aging Cell 8: 221-225, 2009.

5. Hengartner MO: The biochemistry of apoptosis. Nature 407: 770-776, 2000

6. Green DR: Apoptotic pathways: paper wraps stone blunts scissors. Cell 102: 1-4, 2000.
7. Candé C, Cohen I, Daugas E, et al: Apoptosis-inducing factor (AIF): a novel caspase-independent death effector released from mitochondria. Biochimie 84: 215-222, 2002.

8. Constantinou C, Papas KA and Constantinou AI: Caspaseindependent pathways of programmed cell death: the unraveling of new targets of cancer therapy? Curr Cancer Drug Targets 9: 717-728, 2009.

9. Desch CE, Somerfield MR, Krause C, et al: Colorectal cancer surveillance: 2005 update of an American Society of Clinical Oncology practice guideline. J Clin Oncol 23: 8512-8519, 2005.

10. Perraud A, Nouaille M, Akil H, et al: Predictive value of retinoid acid receptors in human colorectal cancer. Exp Ther Med 2: 491-497, 2011.

11. Wu CH, Rastegar M, Gordon J and Safa AR: $\beta(2)$-microglobulin induces apoptosis in HL-60 human leukemia cell line and its multidrug resistant variants overexpressing MRP1 but lacking Bax or overexpressing P-glycoprotein. Oncogene 20: 7006-7020, 2001.

12. Gown AM and Willingham MC: Improved detection of apoptotic cells in archival paraffin sections: immunohistochemistry using antibodies to cleaved caspase 3. J Histochem Cytochem 50: 449-454, 2002.

13. Hammer $\varnothing$, Harper DAT and Ryan PD: PAST: Paleontological Statistics Software Package for Education and Data Analysis. Palaeontologia Electronica 4: 1-9, 2001.

14. Tanaka K, Nagaoka S, Takemura T, et al: Incidence of apoptosis increases with age in colorectal cancer. Exp Gerontol 37: 1469-1479, 2002.

15. Kwon Y and Magnuson BA: Aging alters acute apoptotic response to azoxymethane in the colon of rats. Exp Gerontol 42: 1154-1161, 2007.

16. West NJ, Courtney ED, Poullis AP and Leicester RJ: Apoptosis in the colonic crypt, colorectal adenomata, and manipulation by chemoprevention. Cancer Epidemiol Biomarkers Prev 18: 1680-1687, 2009.

17. Millan A and Huerta S: Apoptosis-inducing factor and colon cancer. J Surg Res 151: 163-170, 2007.

18. Oeseburg H, de Boer RA, van Gilst WH and van der Harst P: Telomere biology in healthy aging and disease. Eur J Physiol 459: 259-268, 2010.

19. Leonardos L, Butler LM, Hewett PJ, Zalewski PD and Cowled PA: The activity of caspase-3-like proteases is elevated during the development of colorectal carcinoma. Cancer Lett 143: 29-35, 1999.

20. Li M, Xiao ZQ, Chen ZC, et al: Proteomic analysis of the aging-related proteins in human normal colon epithelial tissue. J Biochem Mol Biol 40: 72-81, 2007.

21. Pollack M, Phaneuf S, Dirks A and Leeuwenburgh C: The role of apoptosis in the normal aging brain, skeletal muscle, and heart. Ann N Y Acad Sci 959: 93-107, 2002.

22. Holt PR, Kozuch P and Mewar S: Colon cancer and the elderly: from screening to treatment in management of GI disease in the elderly. Best Pract Res Clin Gastroenterol 23: 889-907, 2009.

23. Colonna M, Bossard N, Remontet L and Grosclaude P; FRANCIM Network: Changes in the risk of death from cancer up to five years after diagnosis in elderly patients: a study of five common cancers. Int J Cancer 127: 924-931, 2009. 